\title{
Ultrastructural immunocytochemistry shows impairment of RNA pathways in skeletal muscle nuclei of old mice: A link to sarcopenia?
}

\author{
Maria Assunta Lacavalla,* Barbara Cisterna,* Carlo Zancanaro, Manuela Malatesta \\ Department of Neurosciences, Biomedicine and Movement Sciences, University of Verona, Italy \\ *These authors contributed equally
}

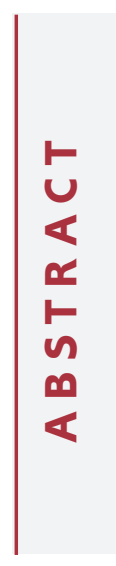

\begin{abstract}
During aging, skeletal muscle is affected by sarcopenia, a progressive decline in muscle mass, strength and endurance that leads to loss of function and disability. Cell nucleus dysfunction is a possible factor contributing to sarcopenia because aging-associated alterations in mRNA and rRNA transcription/maturation machinery have been shown in several cell types including muscle cells. In this study, the distribution and density of key molecular factors involved in RNA pathways namely, nuclear actin (a motor protein and regulator of RNA transcription), 5-methyl cytosine (an epigenetic regulator of gene transcription), and ribonuclease A (an RNA degrading enzyme) were compared in different nuclear compartments of late adult and old mice myonuclei by means of ultrastructural immunocytochemistry. In all nuclear compartments, an age-related decrease of nuclear actin suggested altered chromatin structuring and impaired nucleus-to-cytoplasm transport of both mRNA and ribosomal subunits, while a decrease of 5-methyl cytosine and ribonuclease $\mathrm{A}$ in the nucleoli of old mice indicated an age-dependent loss of rRNA genes. These findings provide novel experimental evidence that, in the aging skeletal muscle, nuclear RNA pathways undergo impairment, likely hindering protein synthesis and contributing to the onset and progression of sarcopenia.
\end{abstract}

Key words: Transmission electron microscopy; nuclear actin; 5-methylcytosine; ribonuclease A.

Correspondence: Manuela Malatesta, Department of Neurosciences, Biomedicine and Movement Sciences, University of Verona, Strada Le Grazie 8, 37134 Verona, Italy. E-mail: manuela.malatesta@univr.it

Contributions: $\mathrm{MM}$ and $\mathrm{BC}$ contributed to the study conception and design; MAL and BC performed experiments and analyzed data; MAL and $\mathrm{BC}$ interpreted data and wrote the first draft of the manuscript; $\mathrm{MM}$ and $\mathrm{CZ}$ supervised the project; all authors read and commented the manuscript and approved its final version.

Conflict of interest: The authors declare no conflict of interest.

Funding: This work was supported by intramural (Department of Neurosciences, Biomedicine and Movement Sciences, University of Verona) funding to $\mathrm{CZ}$ and $\mathrm{MM}$. 


\section{Introduction}

Aging severely affects skeletal muscle with a progressive decline in muscle mass and a parallel decrease in strength and endurance. This condition, known as sarcopenia, leads to frailty, functional loss and disability with significant socioeconomic consequences. ${ }^{1}$ A single pathogenic cause for sarcopenia has not yet been settled in. Several contributing factors to sarcopenia have been proposed e.g., impairment of proteolytic and autophagic pathways, ${ }^{2}$ loss of satellite cells, ${ }^{3}$ mitochondrial dysfunction, ${ }^{4}$ chromatin dysregulation, ${ }^{5}$ rDNA genome instability, ${ }^{6}$ and depletion of myonuclei. ${ }^{7}$

Skeletal muscle is a highly plastic tissue and understanding the regulatory mechanisms that underlie the sarcopenic drive is indeed essential to develop interventional strategies. In particular, protein homeostasis is progressively lost in skeletal muscle during aging, ${ }^{8}$ likely contributing to muscle loss and dysfunction. ${ }^{9}$ A balanced protein metabolism in the skeletal muscle tissue can be operated by the regulation of both gene expression and protein degradation, as well as the control of mRNA stability and translation rate. ${ }^{10}$ Functional alterations of the mRNA-processing machinery are responsible for several age-related diseases (reviewed in ${ }^{11}$ ) thereby supporting the concept that aging-associated alterations of the gene expression pathways are not necessarily and exclusively related to genomic mutations but may be also associated with impairments in the transcription and/or splicing of pre-mRNAs.

The processing and maturation of mRNA to be exported to the cytoplasm imply several modification steps, where many processing factors operate in a chronologically and spatially defined order and, for the most, co-transcriptionally (reviewed $\mathrm{in}^{12}$ ). The perichromatin fibrils (PFs) are the in situ form of nascent transcripts (reviewed in ${ }^{13}$ ) as well as the splicing, ${ }^{14}$ and end-processing products therefrom: ${ }^{15}$ PFs are ribonucleoprotein structures morphologically recognized at transmission electron microscopy (TEM) as fine fibrils that mainly locate along the border of condensed chromatin. ${ }^{16}$ The factors involved in mRNA transcription and maturation are stored, assembled and modified in the interchromatin granules $\left(\mathrm{IGs}^{17}\right)$, which occur as clusters in the interchromatin space. The already spliced mRNA is stored in the perichromatin granules (PGs): these roundish structures locate at the border of condensed chromatin and act as vectors for the intranuclear and the nucleus-to-cytoplasm transport of mRNA. ${ }^{13}$

Previous studies on different cell types demonstrated that, during aging, the structure, regulation and function of mRNA are affected: ${ }^{18}$ the alterations in the mRNA transcription and maturation machinery are associated with a decrease in RNA polymerase II and a partial relocation and/or quantitative modification of factors involved in mRNA processing along with accumulation of PFs and PGs. ${ }^{19-23}$ The pre-ribosome biogenesis and ribosome export to the cytoplasm are affected by aging as well, as demonstrated by the reorganization of the nucleolar components, ${ }^{21,24}$ the variation in size of nucleoli, ${ }^{25}$ and the accumulation of alterations of the nucleolar structure. ${ }^{26}$

Evidence has already been provided of morphological and functional modifications of myonuclei during aging. ${ }^{21,27}$ In the nuclei of skeletal myofibers as well as in cultured primary myoblasts ${ }^{28}$ from aged animals, a smaller size and a significant increase in condensed chromatin are accompanied by a decrease in RNA transcription and maturation, as demonstrated by the lower immunolabelling density of hybrid DNA/RNA, RNA polymerase II and splicing factors. ${ }^{21,29}$ These findings support the concept that reduced/impaired RNA transcription and processing should be included among the multiple causes of sarcopenia. ${ }^{5-7}$ In myonuclei of old rodents, the end-processing and nucleus-to-cytoplasm export of RNAs proved to be also affected, as shown by the accu- mulation of PFs, polyadenylated tails (i.e., markers of mature RNA) and PGs in the interchromatin space, ${ }^{21,29}$ as well as increase and/or redistribution of cleavage factors. ${ }^{21,27,29}$

To get a deeper insight into the nuclear pathways involved in the synthesis, transport and degradation of RNAs in skeletal muscle nuclei during aging, we compared the distribution and relative amount of nuclear actin, 5-mC and ribonuclease (RNase) A in myonuclei of rectus femoris muscles from old and late adult mice. As a motor protein, nuclear actin is a marker of intranuclear motility while also being a regulator of RNA transcription; ${ }^{30}$ the methylated form of the DNA base cytosine, 5-methyl cytosine $(5-\mathrm{mC})$ is an epigenetic regulator of gene transcription ${ }^{31}$ involved in chromatin organization; and RNase A is responsible for the intranuclear degradation of RNA. ${ }^{32}$

We used quantitative ultrastructural immunocytochemistry as a suitable experimental approach to detect and locate in well-defined nuclear domains these molecular factors that play crucial roles in nuclear physiology. The differences we observed in the myonuclei of old (28-months-old) mice $v s$. their late adult counterpart reinforce the notion that during aging myonuclei undergo an impairment of RNA pathways, thereby further supporting a myonuclear involvement in the sarcopenia of aging.

\section{Materials and Methods}

\section{Animals and tissue processing}

Male BALB/c mice aged 19 months (late adult, $\mathrm{n}=3$ ) and 28 months (old, $n=3$ ) were used in this study. Late adult mice were selected as an appropriate control to detect the nuclear modifications that are strictly related to the old age, avoiding the results be influenced by factors other than age.

The animals were bred under controlled environmental conditions with a $12 \mathrm{~h}$ light/dark cycle and fed ad libitum on a standard commercial chow. The experiment was carried out in accordance with the National and international legislation, and the experimental protocol was approved by the Italian Ministry of Health (ref.: 538/2015-PR).

Mice were deeply anaesthetized with pentobarbital $(50 \mathrm{mg} / \mathrm{Kg}$ i.p.) and then perfused via the ascending aorta with a brief prewash with $0.09 \% \mathrm{NaCl}$ solution followed by $300 \mathrm{~mL}$ of a ready-to-use fixative solution containing $4 \%$ buffered formalin in $0.1 \mathrm{M}$ phosphate buffer, $\mathrm{pH}$ 7.4. The right and left rectus femoris muscles were quickly removed and further fixed by immersion with $4 \%$ paraformaldehyde and $0.5 \%$ glutaraldehyde in $0.1 \mathrm{M}$ phosphate buffer saline (PBS) $\mathrm{pH} 7.4$ for $2 \mathrm{~h}$ at $4^{\circ} \mathrm{C}$, incubated in $0.5 \mathrm{M}$ $\mathrm{NH}_{4} \mathrm{Cl}$ in $\mathrm{PBS}$ for $30 \mathrm{~min}$ at room temperature to block the free aldehyde groups, dehydrated with graded ethanol, and embedded in LRWhite resin.

\section{Ultrastructural immunocytochemistry}

Ultrathin sections (70-90 nm thick) were cut, collected on Formvar-carbon-coated nickel grids and used for the immunocytochemical analyses on the nuclei of the rectus femoris myofibers.

In order to evaluate the nuclear distribution of RNA processing factors, longitudinally-cut sections of rectus femoris muscles were incubated with the following probes: a mouse monoclonal antibody directed against the active phosphorylated form of RNA polymerase II (diluted 1:10, Abcam, Cambridge, UK); rabbit polyclonal antibodies directed against nuclear actin, diluted 1:50 (Sigma-Aldrich, Milan, Italy), 5-mC, diluted 1:100 (GeneTex, Irvine, CA, USA) and RNase A (the probe recognizes both active and inactive form of the enzyme), diluted 1:100 (Abcam). According to Cmarko et al., ${ }^{14}$ the ultrathin sections were floated 
for 3 min on normal goat serum (NGS) diluted 1:100 in PBS and then incubated at $4^{\circ} \mathrm{C}$ for $17 \mathrm{~h}$ with the primary antibodies diluted in PBS containing $0.05 \%$ Tween 20 and $0.1 \%$ bovine serum albumin. After rinsing, the sections were floated on NGS, and incubated for $30 \mathrm{~min}$ at room temperature with the secondary gold-conjugated probes (Jackson Immuno Research Laboratories, West Grove, PA, USA) diluted 1:20 in PBS. A goat anti-mouse antibody conjugated with $6 \mathrm{~nm}$ gold grains and a goat anti-rabbit antibody conjugated with $12 \mathrm{~nm}$ gold grains were used. As control, some grids were incubated without the primary antibody and then processed as described above.

Following to immunolabeling, sections were stained for 35 min at room temperature with Uranyl Less EM stain (Electron Microscopy Sciences, Hatfield, PA, USA), followed by Reynolds' lead citrate for $1 \mathrm{~min}$ to reduce the chromatin contrast and preferentially reveal the ribonucleoprotein nuclear constituents.

In order to verify that RNA degradation is a co-transcriptional process, a double immunolabeling was performed with antibodies directed against RNA polymerase II and RNase A, followed by the specific secondary antibodies conjugated with either 6 or $12 \mathrm{~nm}$ gold, respectively. For the fine specific visualization of RNA in the PFs, the sections were then floated onto $0.2 \mathrm{M}$ terbium citrate for $30 \mathrm{~min}$ at room temperature, rapidly rinsed with water and dried. ${ }^{33}$ The samples were observed in a Philips Morgagni TEM operating at $80 \mathrm{kV}$ and equipped with Megaview III camera for digital image acquisition.

For nuclear actin, 5-mC and RNAse A, a semiquantitative assessment of the immunolabeling was carried out by estimating the gold grain density on selected nuclear compartments in sections of muscles from different mice treated in the same run. The area of different nuclear compartments was measured using the ImageJ software (NIH) on 40 randomly selected nuclear micrographs $(x 14,000)$ for each age group. The gold grains were counted, and the labelling density was expressed as number of gold grains $/ \mu \mathrm{m}^{2}$. The following nuclear compartments were considered: condensed chromatin, nucleolus and interchromatin space (obtained by subtracting the areas of both condensed chromatin and nucleolus from the total area of the myonucleus). In eight myonuclei from each age group, the percentage of the interchro- matin space immunolabelled for RNAse A occurring on IGs was evaluated.

The background level for all antibodies was evaluated on section areas devoid of tissue and proved to be negligible (see Figure 2 legend).

\section{Statistical analysis}

Data for each variable were pooled according to the age group and presented as mean \pm standard error of the mean (SEM). Statistical group-group comparison was performed with the MannWhitney test setting statistical significance at alpha $\leq 0.05$.

\section{Results and Discussion}

The myonuclei of old and late adult mice showed a similar ultrastructural organization; instead, interesting differences were observed in the distribution and density of the investigated nuclear molecular factors.

Nuclear actin (Figure 1A) was found to locate on condensed chromatin, in the interchromatin space (namely, on PFs and IGs) and in the nucleolus at both ages, but the immunolabeling density was significantly lower in myonuclei of old mice compared to late adult animals for all the considered nuclear compartments (condensed chromatin, $\mathrm{p}<0.001$; nucleolus, $\mathrm{p} \leq 0.001$; interchromatin space, $\mathrm{p} \leq 0.001$ ) (Figure $2 \mathrm{~A}$ ). Nuclear actin is a motor protein involved in several processes inclusive of movement and organization of chromatin (reviewed $\mathrm{in}^{30}$ ). The decrease of nuclear actin on condensed chromatin would thus support the hypothesis that aging leads to alterations in chromatin structuring. Nuclear actin is also involved in the regulation of mRNA and rRNA transcription and is crucial in the active nuclear-to-cytoplasm transport of both mRNA $\left(\right.$ reviewed $\mathrm{in}^{34}$ ) and pre-ribosomal subunits. ${ }^{35,36}$ Therefore, the significantly lower amount of nuclear actin observed in the interchromatin space and nucleoli of old animals (Figure 2A) is consistent with the previously shown reduction in transcriptional rate and impairment of RNA export in the aged skeletal muscle. ${ }^{22,29}$ As for the nucleolus, a previous study ${ }^{21}$ on myonuclei of old rats showed
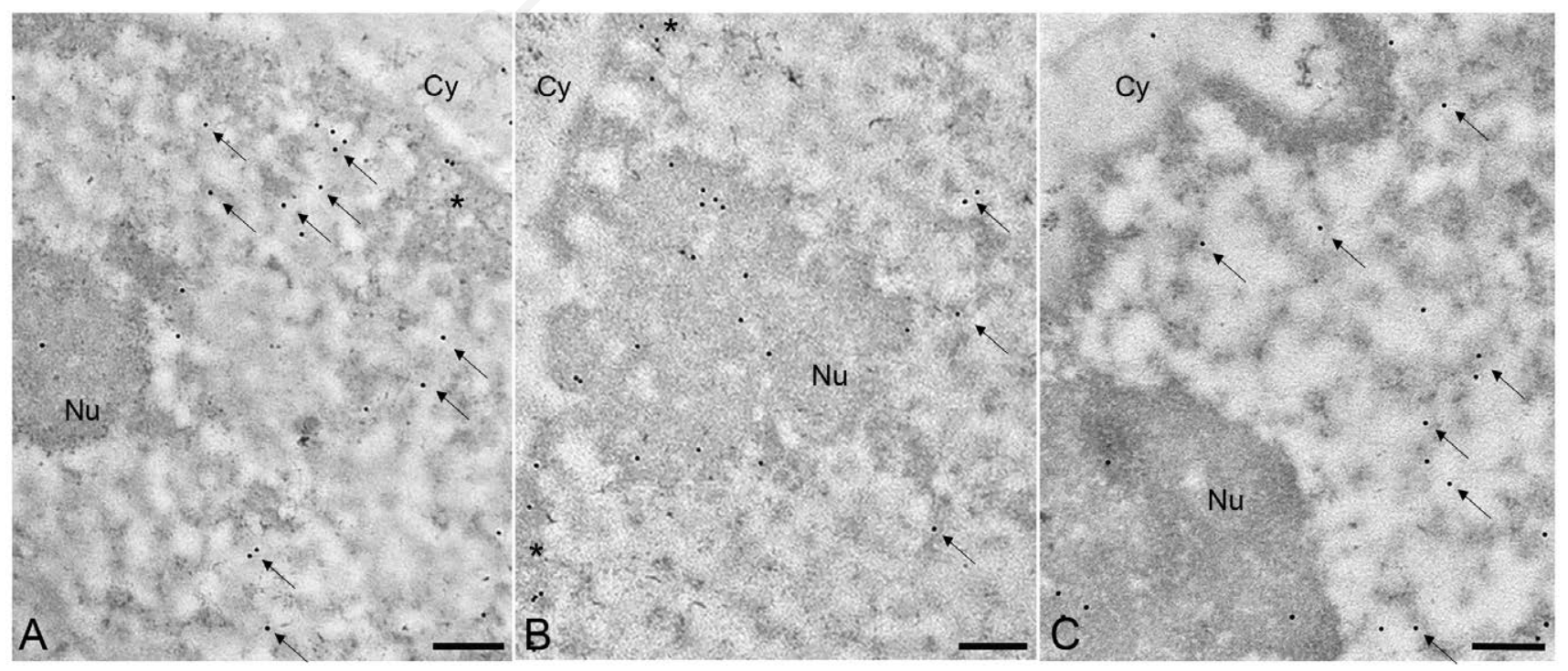

Figure 1. Immunoelectron microscopy of myonuclei from late adult mice immunolabelled for nuclear actin (A), 5-mC (B) and RNase $\mathrm{A}(\mathrm{C})$. All antibodies label perichromatin fibrils (arrows) in the interchromatin space and nucleolus ( Nu). Note the labelling on the condensed chromatin clumps (asterisks) for nuclear actin and 5-mC (A, B). Cy, cytoplasm. Scale bars: $200 \mathrm{~nm}$. 
a reduction in rRNA transcription and processing as indicated by decrease of the dense fibrillar component ${ }^{21}$ where these processes are known to take place. ${ }^{37}$ In the same myonuclei, an increase in the nucleolar granular component (where pre-ribosomes are stored before being exported to the cytoplasm ${ }^{38}$ ), suggests that ribosomal subunits accumulate in the nucleolus. The lower amount of actin in the myonuclei of old mice may thus be also indicative of an impaired export of the ribosomal subunits in aging. Consistently, using a biochemical fractionation strategy, Cutler et al. ${ }^{23}$ observed higher amount of ribosomal proteins in myonuclei isolated from aged mice, despite the decrease in ribosome biogenesis found in skeletal muscle of old mice by microarray analysis. ${ }^{39}$

The labelling for $5 \mathrm{~m}-\mathrm{C}$ occurred on condensed chromatin, the interchromatin space (in particular on PFs) and the nucleolus (Figure 1B). Quantitative evaluation of the immunolabeling revealed similar densities of $5 \mathrm{~m}-\mathrm{C}$ on condensed chromatin $(p=0.43)$ and interchromatin space $(p=0.14)$ of myonuclei from late adult and old mice. On the contrary, $5 \mathrm{~m}-\mathrm{C}$ density was significantly lower in nucleoli of old $v s$. late adult mice $(\mathrm{p}<0.001)$ (Figure 2B). According to current knowledge, 5-mC is mainly involved in the regulation of gene transcription, ${ }^{3}$ being generally associated with transcriptional repression; ${ }^{40} 5-\mathrm{mC}$ may also occur as an epigenetic modification in RNA, ${ }^{41,42}$ acting as signal for the mRNA export adaptor ALYREF in the nucleus-to-cytoplasm transports of mature mRNA. ${ }^{43}$ Therefore, the $5-\mathrm{mC}$ labelled PFs in the interchromatin space likely contain mature mRNA ready to leave the nucleus. The presence of 5-mC in silent rRNA genes seems to protect from illicit recombination events that would promote loss of rDNA. ${ }^{44}$ The statistically significant decrease of $5 \mathrm{~m}-\mathrm{C}$ in nucleoli, thus, would make the rRNA genes in old mice more prone to an age-dependent loss, as much as it occurs in murine spleen, brain and liver ${ }^{45}$ and in the human adipose tissue. ${ }^{46}$ This event would be also consistent with the decrease in ribosome biogenesis found in the aged skeletal muscle. ${ }^{39}$

RNase A immunolabeling was found on condensed chromatin, the interchromatin space (namely on PFs and IGs) and the nucleolus (Figure 1C) in both groups of age. Quantitative evaluation revealed that RNase A labelling density on condensed chromatin was similar in late adult and old animals and increased at the limit of statistical significance in the interchromatin space of old myonuclei $(p=0.069)$, whereas it was significantly lower in the nucleolus of old $v s$. late adult mice $(\mathrm{p} \leq 0.001)$ (Figure $2 \mathrm{C})$. RNase $\mathrm{A}$, which is active in skeletal muscle, ${ }^{47}$ is a general RNase that catalyzes the cleavage of RNA on the 3' side of pyrimidine nucleotides..$^{32}$ The presence of RNase A on condensed chromatin suggests an action of this enzyme in this nuclear compartment where RNA plays a direct role in the chromatin structural organization (reviewed $\mathrm{in}^{48}$ ). In the interchromatin space, the immunolabeling for RNase A on IGs (where factors involved in mRNA transcription and maturation are stored, assembled and modified ${ }^{17}$ ) were not statistically significant different in late adult and old mice $(10.77 \% \pm 0.05$ vs. $11.75 \% \pm 0.04$, respectively). The tendency of RNase A to increase in the interchromatin space of old mice could be due to the accumulation of enzyme-containing PFs in the nuclei of old animals. ${ }^{22}$ Interestingly, the co-presence of active RNA polymerase II and RNase A on the same PFs (Figure 3) in both late adult and old mice suggests that mRNA degradation occurs cotranscriptionally, as observed for the splicing and ending processing of the mRNA. ${ }^{49}$ RNase $A$ is involved in the activation of rDNA transcription in several cell types; ${ }^{50}$ thus, the statistically significant lower amount of RNase A in the nucleoli of myonuclei from old mice (Figure 2C) might (directly or indirectly) be related to an age-dependent loss of rRNA genes as suggested by the decreased immunolabeling for 5-mC. Alternatively, as already demonstrated for other factors, ${ }^{51}$ it may be hypothesized that the nucleolus acts
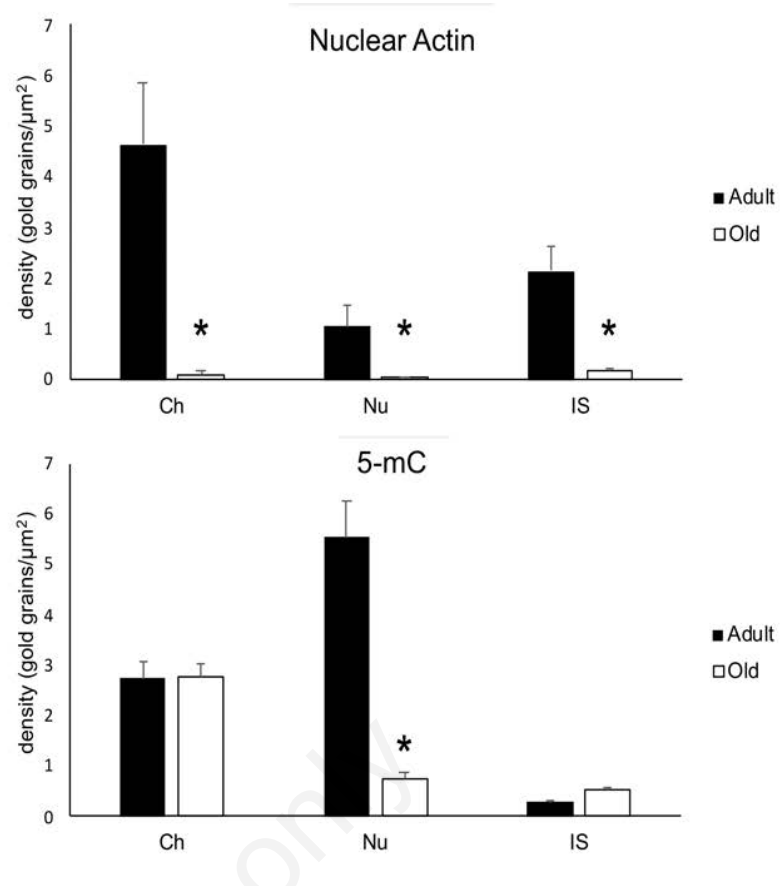

- Adult

口Old

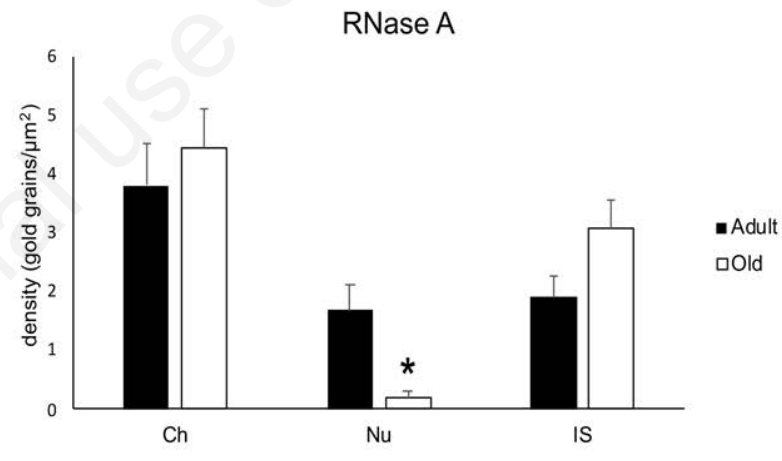

Figure 2. Immunolabeling density of nuclear actin (A), 5-mC (B), RNase $A(C)$ on condensed chromatin $(\mathrm{Ch})$, nucleolus $(\mathrm{Nu})$, interchromatin space (IS) in myonuclei of late adult and old mice. The histograms show the mean value \pm SEM of density expressed as gold grains $/ \mu^{2}$. Statistically significant differences $(p \leq 0.001)$ are indicated by asterisk. Background density was negligible for all probes (nuclear actin, $0.180 .05 ; 5-\mathrm{mC}, 0.45 \pm 0.03$; RNase A, $0.39 \pm 0.08)$.

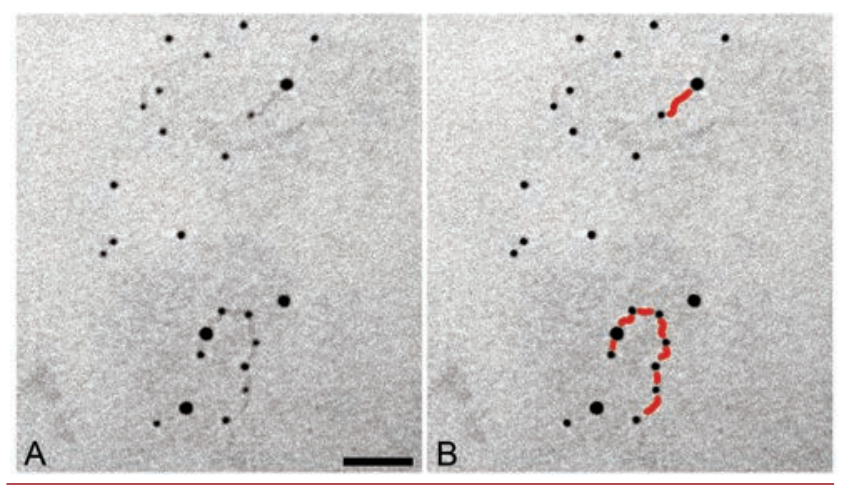

Figure 3. A,B) Transmission electron micrographs of myonuclei from old mice double-immunolabelled for RNA polymerase II (6nm gold grain) and RNase A (12nm gold grain), followed by staining with terbium citrate. B) The RNA of the PFs was digitally colored in red for ease of visualization. Scale bar: $50 \mathrm{~nm}$. 
as a transit and storage site for RNase A during aging. ${ }^{52}$ In fact, mass-spectrometry-based analyses revealed that numerous proteins involved in functions other than ribosome biogenesis are present in the nucleolus, strongly suggesting a multiple role for this organelle, ${ }^{53}$ with important implications in aging. ${ }^{6}$

In conclusion, the fine immunocytochemical analysis carried out in this study provides novel information on the aging-associated changes in the amount of molecular factors involved in chromatin stability as well as transcription, processing and transport of RNAs in myonuclei of old mice, shedding light on the mechanisms underlying alterations of the cell nucleus during aging. In particular, the statistically significant decrease of nuclear actin strongly supports impairment of mRNA transcription and nucleus-to-cytoplasm transport of mRNA and ribosomal subunits, while the decrease of 5-mC and RNase A in nucleoli suggests an age-dependent loss of rRNA genes. These nuclear dysfunctions may hinder protein synthesis and impair the physiological balance between protein anabolism and catabolism typical of the healthy skeletal muscle tissue, ${ }^{54}$ thus contributing to the onset and progression of sarcopenia.

\section{Acknowledgments}

MAL is a PhD student in receipt of a fellowship from the Doctoral Program "Nanoscience and Advanced Technologies" of the University of Verona.

\section{References}

1. Cruz-Jentoft AJ, Baeyens JP, Bauer JM, Boirie Y, Cederholm T, Landi F, et al. Sarcopenia: European consensus on definition and diagnosis: report of the European Working Group on sarcopenia in older people. Age Ageing 2010; 39:412-23.

2. Combaret L, Dardevet D, Béchet D, Taillandier D, Mosoni L, Attaix D. Skeletal muscle proteolysis in aging. Curr Opin Clin Nutr Metab Care 2009;12:37-41.

3. Verdijk LB, Koopman R, Schaart G, Meijer K, Savelberg HH, van Loon LJ. Satellite cell content is specifically reduced in type II skeletal muscle fibers in the elderly. Am J Physiol Endocrinol Metab 2007;292:E151-7.

4. Short KR, Bigelow ML, Kahl J, Singh R, Coenen-Schimke J, Raghavakaimal S, et al. Decline in skeletal muscle mitochondrial function with aging in humans. Proc Natl Acad Sci USA 2005;102:5618-23

5. Pegoraro G, Misteli T. The central role of chromatin maintenance in aging. Aging (Albany NY) 2009;1:1017-22.

6. Tiku V, Antebi A. Nucleolar function in lifespan regulation. Trends Cell Biol 2018;28:662-72.

7. Dirks AJ, Leeuwenburgh C. The role of apoptosis in age-related skeletal muscle atrophy. Sports Med 2005;35:473-83.

8. Brook MS, Wilkinson DJ, Phillips BE, Perez-Schindler J, Philp A, Smith K, et al. Skeletal muscle homeostasis and plasticity in youth and ageing: impact of nutrition and exercise. Acta Physiol (Oxford) 2016;216:15-41.

9. Aversa Z, Zhang X, Fielding RA, Lanza I, LeBrasseur NK. The clinical impact and biological mechanisms of skeletal muscle aging. Bone 2019;127:26-36.

10. Falcone C, Mazzoni C. RNA stability and metabolism in regulated cell death, aging and diseases. FEMS Yeast Res 2018; 18 :foy050.

11. Meshorer E, Soreq H. Pre-mRNA splicing modulations in senescence. Aging Cell 2002;1:10-6.
12. Wahle E, Ruegsegger U. 3'-end processing of pre-mRNA in eukaryotes. FEMS Microbiol Rev 1999;23:277-95.

13. Fakan S. Ultrastructural cytochemical analyses of nuclear functional architecture. Eur J Histochem 2004;48:5-14.

14. Cmarko D, Verschure PJ, Martin TE, Dahmus ME, Krause S, $\mathrm{Fu} \mathrm{XD}$, et al. Ultrastructural analysis of transcription and splicing in the cell nucleus after bromo-UTP microinjection. Mol Biol Cell 1999;10:211-23.

15. Cardinale S, Cisterna B, Sonetti P, Aringhieri C, Biggiogera M, Barabino SML. Subnuclear localization and dynamics of the pre-mRNA 3' end processing factor CFIm68. Mol Biol Cell 2007;18:1282-92.

16. Biggiogera M, Cisterna B, Spedito A, Vecchio L, Malatesta M. Perichromatin fibrils as early markers of transcriptional alterations. Differentiation 2008;76:57-65.

17. Puvion E, Puvion-Dutilleul F. Ultrastructure of the nucleus in relation to transcription and splicing: roles of perichromatin fibrils and interchromatin granules. Exp Cell Res 1996;229:217-25.

18. Cookson MR. Aging - RNA in Development and Disease. Wiley Interdiscip Rev RNA 2012;3:133-43.

19. Malatesta M, Baldelli B, Battistelli S, Fattoretti P, BertoniFreddari C. Aging affects the distribution of the circadian CLOCK protein in rat hepatocytes. Microsc Res Tech 2005;68:45-50.

20. Malatesta M, Fattoretti P, Baldelli B, Battistelli S, Balietti M, Bertoni-Freddari C. Effects of ageing on the fine distribution of the circadian CLOCK protein in reticular formation neurons. Histochem Cell Biol 2007;127:641-7.

21. Malatesta M, Perdoni F, Muller S, Zancanaro C, Pellicciari C. Nuclei of aged myofibres undergo structural and functional changes suggesting impairment in RNA processing. Eur J Histochem 2009;53:e12.

22. Malatesta M, Biggiogera M, Cisterna B, Balietti M, BertoniFreddari C, Fattoretti P. Perichromatin fibrils accumulation in hepatocyte nuclei reveals alterations of pre-mRNA processing during aging. DNA Cell Biol 2010;29:49-57.

23. Cutler AA, Dammer EB, Doung DM, Seyfried NT, Corbett $\mathrm{AH}$, Pavlath GK. Biochemical isolation of myonuclei employed to define changes to the myonuclear proteome that occur with aging. Aging Cell 2017;16:738-49.

24. Malatesta M, Bertoni-Freddari C, Fattoretti P, Caporaloni C, Fakan S, Gazzanelli G. Altered RNA structural constituents in aging and vitamin E deficiency. Mech Ageing Dev 2003;124:175-81.

25. Buchwalter A, Hetzer MW. Nucleolar expansion and elevated protein translation in premature aging. Nat Commun 2017;8:328.

26. Duncan FE, Jasti S, Paulson A, Kelsh JM, Fegley B, Gerton JL. Age-associated dysregulation of protein metabolism in the mammalian oocyte. Aging Cell 2017;16:1381-93.

27. Malatesta M, Giagnacovo M, Costanzo M, Cisterna B, Cardani R, Meola G. Muscleblind-like1 undergoes ectopic relocation in the nuclei of skeletal muscles in myotonic dystrophy and sarcopenia. Eur J Histochem 2013;57:e15.

28. Cisterna B, Giagnacovo M, Costanzo M, Fattoretti P, Zancanaro C, Pellicciari C et al. Adapted physical exercise enhances activation and differentiation potential of satellite cells in the skeletal muscle of old mice. J Anat 2016;228:77183.

29. Malatesta M, Fattoretti P, Giagnacovo M, Pellicciari C, Zancanaro C. Physical training modulates structural and functional features of cell nuclei in type II myofibers of old mice. Rejuvenation Res 2011;14:543-52.

30. Kelpsch DJ, Tootle TL. Nuclear actin: From discovery to func- 
tion. Anat Rec (Hoboken) 2018;301:1999-2013.

31. Kumar S, Chinnusamy V, Mohapatra T. Epigenetics of modified DNA bases: 5-methylcytosine and beyond. Front Genet 2018;9:640.

32. Hahn U, Desai-Hahn R, Rüterjans H. 1H and 15N NMR investigation of the interaction of pyrimidine nucleotides with ribonuclease A. Eur J Biochem 1985;146:705-12.

33. Biggiogera M, Masiello I. Visualizing RNA at electron microscopy by terbium citrate. Methods Mol Biol 2017;1560:277-83.

34. Kristó I, Bajusz I, Bajusz C, Borkúti P, Vilmos P. Actin, actinbinding proteins, and actin-related proteins in the nucleus. Histochem Cell Biol 2016;145:373-88.

35. Cisterna B, Necchi D, Prosperi E, Biggiogera M. Small ribosomal subunits associate with nuclear myosin and actin in transit to the nuclear pores. FASEB J 2006;20:1901-3.

36. Cisterna B, Malatesta M, Dieker J, Muller S, Prosperi E, Biggiogera M. An active mechanism flanks and modulates the export of the small ribosomal subunits. Histochem Cell Biol 2009;131:743-53.

37. Biggiogera M, Malatesta M, Abolhassani-Dadras S, Amalric F, Rothblum LI, Fakan S. Revealing the unseen: the organizer region of the nucleolus. J Cell Sci 2001;114:3199-205.

38. Schwarzacher HG, Wachtler F. The nucleolus. Anat Embryol (Berl) 1993;188:515-36.

39. Kirby TJ, Lee JD, England JH, Chaillou T, Esser KA, McCarthy JJ. Blunted hypertrophic response in aged skeletal muscle is associated with decreased ribosome biogenesis. J Appl Physiol (1985) 2015;119:321-7.

40. Alison I, Bernstein, Peng J. High-throughput sequencingbased mapping of cytosine modifications. In: Y. G. Zheng, Editor. Epigenetic Technological Applications. Academic Press; 2015. p. 39-53.

41. Masiello I, Biggiogera M. Ultrastructural localization of 5methylcytosine on DNA and RNA. Cell Mol Life Sci 2017;74:3057-64.

42. Trixl L, Lusser A. The dynamic RNA modification 5-methylcytosine and its emerging role as an epitranscriptomic mark. Wiley Interdiscip Rev RNA 2019;10:e1510.
43. Yang X, Yang Y, Sun BF, Chen YS, Xu JW, Lai WY, et al. 5methylcytosine promotes mRNA export-NSUN2 as the methyltransferase and ALYREF as an $\mathrm{m} 5 \mathrm{C}$ reader. Cell Res 2017;27:606-25.

44. Guetg C, Lienemann P, Sirri V, Grummt I, Hernandez-Verdun D, Hottiger MO, et al. The NoRC complex mediates the heterochromatin formation and stability of silent rRNA genes and centromeric repeats. EMBO J 2010;29:2135-46.

45. Gaubatz JW, Cutler RG. Age-related differences in the number of ribosomal RNA genes of mouse tissues. Gerontology 1978;24:179-207.

46. Zafiropoulos A, Tsentelierou E, Linardakis M, Kafatos A, Spandidos DA. Preferential loss of 5S and 28S rDNA genes in human adipose tissue during ageing. Int $\mathrm{J}$ Biochem Cell Biol 2005;37:409-15.

47. Reilly ME, Erylaz EI, Amir A, Peters TJ, Preedy VR. Skeletal muscle ribonuclease activities in chronically ethanol-treated rats. Alcohol Clin Exp Res 1998;22:876-83.

48. Thakur J, Henikoff S. Architectural RNA in chromatin organization. Biochem Soc Trans 2020;48:1967-78.

49. Masiello I, Siciliani S, Biggiogera M. Perichromatin region: a moveable feast. Histochem Cell Biol 2018;150:227-33.

50. Li S, Hu GF. Angiogenin-mediated rRNA transcription in cancer and neurodegeneration. Int J Biochem Mol Biol 2010;1:2635 .

51. Boisvert FM, van Koningsbruggen S, Navascués J, Lamond AI. The multifunctional nucleolus. Nat Rev Mol Cell Biol 2007;8:574-85.

52. Costanzo M, Cisterna B, Zharskaya OO, Zatsepina OV, Biggiogera M. Discrete foci containing RNase A are found in nucleoli of HeLa cells after aging in culture. Eur J Histochem 2011;55:e15.

53. Ahmad Y, Boisvert FM, Gregor P, Cobley A, Lamond AI. NOPdb: nucleolar proteome database-2008 update. Nucleic Acids Res 2009;37:D181-4.

54. Schiaffino S, Dyar KA, Ciciliot S, Blaauw B, Sandri M. Mechanisms regulating skeletal muscle growth and atrophy. FEBS J 2013;280:4294-314.

Received for publication: 15 February 2021. Accepted for publication: 15 March 2021.

This work is licensed under a Creative Commons Attribution-NonCommercial 4.0 International License (CC BY-NC 4.0).

(C) Copyright: the Author(s), 2021

Licensee PAGEPress, Italy

European Journal of Histochemistry 2021; 65:3229

doi:10.4081/ejh.2021.3229 